\title{
Healthy workplaces in Europe and Malaysia
}

\begin{abstract}
It is estimated that we spend at least a third of our working lives in the workplace and the duration of this, due to the extension of working lives through legislative changes and increased pension ages, is set to increase. Ageing of the workforce is a growing concern but health and safety issues cannot be used as an excuse for not employing older workers. A healthy workplace is one where the risks are managed and where workers and their managers work together to improve the work environment and protect the health of the workers. Furthermore, linking this to personal health resources and the local community can improve the health of all involved. Within the workplace this includes both the psychosocial and physical work environment. To create a healthy workplace there is a need to ensure risk management measures are in place and our older workers participation in risk assessment and risk reduction programmes. In addition to this, targeted occupational health promotion programmes may be beneficial. There are few integrated policies with regard to age and work but research does identify good practice, including participation of employees in change measures, senior management commitment and taking a life-course approach. While there are challenges in relation to age-related change, the work ability concept can improve understanding. The use of a comprehensive approach such as Age Management can help employers who have a critical role in making the workplace ageready.
\end{abstract}

Keyword: Healty and safety; Workplace injury; Stress; Work ability; Europe; Malaysia 